\title{
Amerika
}

Mémoires, identités, territoires

12 | 2015

La mort : imaginaires et sociétés

Mélanges

\section{Julio Cortázar y Gonçalo M. Tavares : el juego de todos los juegos}

Celina Martins

https://doi.org/10.4000/amerika.6253

\section{Résumés}

Español English

Este artículo comparatista se propone estudiar la significación plural del juego del lenguaje en Historias de Cronopios y de Famas (1962) de Julio Cortázar y la serie O Bairro (2001-2010) del portugués Gonçalo M. Tavares. Cortázar cuestiona la rutina del lenguaje prefabricado, recorriendo a la invención irónica. Tavares construye un proyecto de barrio que es un juego utópico de deconstrucción del canon literario al transformar escritores argentinos como Juarroz y Cortázar en dobles parodiados que revelan una crítica de sus dilemas, obsesiones y puntos de vista, rechazando el pensamiento unilateral en un ritual de reescritura.

This paper proposes a comparative study of the plus-signification of language games in Cronopios and Famas (1962) by Julio Cortazar and in the series $O$ Bairro (2001) by portuguese writer Gonçalo M. Tavares. Cortázar questions the routine of prefabricated language, by resorting to ironic invention. Tavares constructs a neighbourhood project, i.e., an utopian game of deconstruction of the literary canon, by transforming Argentinian writers, namely Juarroz and Cortázar, into parodied doubles who reveal criticism of their dilemmas, obsessions and viewpoints by rejecting unilateral thinking in a rewriting ritual.

\section{Entrées d'index}

Keywords: game, creation, subversion, rewriting, parody, utopia

Palabras claves: juego, creación, subversión, reescritura, parodia, utopia

\section{Texte intégral}

El juego crea su propio mundo, donde existe otro orden, otro espacio, otro tiempo, un orden sin fin ni intención externa al propio juego, una actividad que vuelve a empezar 
siempre. De acuerdo con la clasificación de Caillois, el simulacro ("mimicry") ${ }^{1}$ es la capacidad de evadirse simulando ser otro, tal como sucede en la representación teatral. La regla del juego es única : el actor fascina al espectador, evitando que una falta de coherencia lo conduzca a rechazar la ilusión vivida como algo más real que la realidad. El juego moviliza, transforma, enfrenta y por ello mismo reúne : inspira comunidad y libertad. Es precisamente esta libertad de invención que caracteriza la escritura del juego en Julio Cortázar y del autor portugués Gonçalo M. Tavares. Nuestro análisis comparatista se propone reflexionar sobre el sentido plural del juego en Cortázar y Tavares, explorando el lenguaje de la subversión en Historias de Cronopios y de Famas y la serie $O$ Bairro, constituida por diez textos ${ }^{2}$.

2 Escritos entre 1952 y 1959, los microrelatos de Historias de Cronopios y de Famas cuestionan la norma establecida, la rutina de la palabra muerta, la rutina del lenguaje prefabricado a través de la invención irónica. Desde 2002, Tavares construye un proyecto de barrio 3 que es un juego de deconstrucción del canon literario al transformar escritores clásicos como Juarroz y Cortázar en dobles parodiados que revelan una crítica de sus obsesiones y sus puntos de vista, rechazando el pensamiento unilateral.

\section{Cortázar : el juego como creación}

Para Maturo, Cortázar concibe el juego según el modelo mágico de los surrealistas, es "un juego significante capaz de destruir las aparencias y revelar la escondida estructura de la realidad"4. Todos los textos de la primera parte de Historias de Cronopios y de Famas presentan un manual de instrucciones que subvierte de forma jocosa el discurso del usuario comercial : el narrador indica instrucciones que no tienen ningún sentido práctico, son divagaciones lúdicas que provocan la complicidad inmediata del lector y lo situan más allá de un mero juego gratuito. Según Maturo, estas instrucciones representan "un elemento de choque ante la comodidad mental, la seguridad y el confort adquiridos" 5 . Hay textos que invitan a ver más allá del juego, buscando una interacción más profunda con el lector y el acceso a una realidad segunda. En "Preámbulo a las instrucciones para dar cuerda a un reloj", el lenguaje irónico de Cortázar es una provocación que incentiva al lector a repensar el riesgo de los hábitos automatizados. El texto nos invita a pensar la alienación del hombre que se dejó atrapar por el ritmo mecanizado del reloj, imponiendo una continua carrera contra el tiempo. El hombre ha caído en una emboscada, se ha dejado dominar por un tiempo encapsulado en un objeto : "Piensa en esto : cuando te regalan un reloj te regalan un pequeño infierno florido, una cadena de rosas, un calabozo de aire"6. La verdadera dimensión temporal no está inscrita en el movimiento mecánico de un reloj : el hombre ha perdido la dimensión ritual del tiempo. Él permanece atado a un tiempo lineal, alejado del ámbito primordial donde coexisten todos los tiempos : la zona sagrada. El reloj representa lo que ha sido consumido : "Te regalan la necesidad de darle cuerda todos los días, la obligación de darle cuerda para que siga siendo un reloj; te regalan la obsesión de atender a la hora exacta en las vitrinas de las joyerías, en el anuncio por la radio, en el servicio telefónico"7. El hombre se vuelve en objeto del reloj, se cosifica : "No te regalan un reloj, tú eres el regalado, a ti te ofrecen para el cumpleaños del reloj"8. Cortázar ironiza acerca de cómo el hombre no busca más una comunicación duradera y profunda con el tiempo por lo que sucumbe a una relación de dependencia al ser esclavo de sus invenciones.

4 Cortázar construye personajes que recrean la mirada lúdica del niño en estado de deslumbramiento, habitado por el juego de reinventar los múltiplos mundos a su alrededor. Tal como veremos en $O$ Barrio de Tavares, Cortázar elabora un juego poético-humorístico al concebir los cronopios como seres que surgen de una cosmovisión surrealista9 ${ }^{9}$ dado que aparecen bajo el influjo de un sueño despierto :

Yo estaba una noche en el teatro des Champs Elysées, había un concierto que me interesaba mucho, yo estaba solo, en lo más alto del teatro porque era lo más barato. Hubo un entreacto y toda la gente salió, a fumar y demás. Yo no tuve ganas de salir y 
me quedé sentado en mi butaca [...] de golpe vi (aunque esto de ver no sé si hay que tomarlo en un sentido directamente sensorial o fue una visión de otro tipo, la visión que podés tener cuando cerrás los ojos o cuando evocás alguna cosa y la ves con la memoria) en el aire de la sala del teatro, vi flotar unos objetos cuyo color era verde, como si fueran globitos, globos verdes que se desplazaban en torno mío. Pero, insisto, eso no era una cosa tangible, no era que yo los estuviera «viendo» tal cual. Aunque de alguna manera sí los estaba viendo. Y junto con la aparición de esos objetos verdes, que parecían inflados como globitos o como sapos o algo así, vino la noción de que esos eran los cronopios. La palabra vino simultáneamente con la visión. ${ }^{10}$

Como señala Garfield, Cortázar entra en "el ambiente del sueño en que es posible descubrir correspondencias no lógicas sino analógicas entre mundos distanciados"11. Para Cortázar, el sueño es un lenguaje innovador, es "la parte auténtica de la realidad que se debe cultivar dentro de lo cotidiano"12. La aparición de los cronopios nos revela como lo indecible brota de un ser poroso, abierto a la irrupción de una realidad segunda que se sobrepone a la realidad factual. El escritor reinvidica el uso de la palabra como un juego generador de nuevos sentidos que exigen la constante creación del lenguaje. Cortázar propone la descolocación, el desorden de lo real para sacar al lector de las casillas, ofreciéndole lo inesperado, invitándole a vislumbrar los intersticios y el lado excéntrico de las cosas de manera a pensar otros modos de existencia.

$6 \quad$ La creación de los cronopios y de los famas no es un simple juego de contraste en relación a la profesión o actividad que ambos cumplen, se trata de mostrar cómo los cronopios se distinguen de los famas porque absorben lo real y lo transforman de forma poética y lúdica. El cronopio introduce la lógica del juego, que según Maturo "irrumpe en la vida ordenada y utilitaria" para revelar la "inconsistencia y absurdidad"13 de lo cotidiano.

$7 \quad$ El cronopio se integra en el modelo del homo ludens, es un ser instalado en la orilla de lo maravilloso que inventa un lenguaje propio, inaugurando un nuevo cronos, una nueva mirada de diversión, tal como se observa en el relato "En lo Particular y Universal" :

Un cronopio iba a lavarse los dientes junto a su balcón, y poseído de una grandísima alegría al ver el sol de la mañana y las hermosas nubes que corrían por el cielo, apretó enormemente el tubo de pasta dentífrica y la pasta empezó a salir en una larga cinta rosa. Después de cubrir su cepillo con una verdadera montaña de pasta, el cronopio se encontró con que le sobraba todavía una cantidad, entonces empezó a sacudir el tubo en la ventana y los pedazos de pasta rosa caían por el balcón a la calle donde varios famas se habían reunido a comentar las novedades municipales. Los pedazos de pasta rosa caían sobre los sombreros de los famas, mientras arriba el cronopio cantaba y se frotaba los dientes lleno de contento. Los famas se indignaron ante esta increíble inconsciencia del cronopio, y decidieron nombrar una delegación para que lo imprecara inmediatamente, con lo cual la delegación formada por tres famas subió a la casa del cronopio y lo increpó, diciéndole así :

-Cronopio, has estropeado nuestros sombreros, por lo cual tendrás que pagar.

Y después, con mucha más fuerza :

-iCronopio, no deberías derrochar así la pasta dentífrica!14

$8 \quad$ El juego de los cronopios revela su modo irreverente de cuestionar las actividades cotidianas, los sistemas y las ideologías. En un juego de metamorfosis, la pasta dentífrica se convierte en una cinta color rosa que vuela, reflejando la exploración de la dimensión humorística, que deconstruye la seriedad de los famas, prisioneros de la "Gran Costumbre" 15 y del racionalismo cartesiano.

9 A la manera de los dadaístas y los surrealistas como Picabia, Duchamp y Dalí que crean objetos innovadores a partir de objetos simples que cesan de cumplir sus finalidades normales, Cortázar se distancia también del empleo corriente de los objetos, radicalmente transformados por el humor. En el relato "Relojes" pone en escena a un 
cronopio que inventó el reloj alcaucil. Esta invención deconstruye el gesto rutinario de dar cuerda al reloj del fama que representa al funcionario burgués, prisionero de sus ideas establecidas. El relato breve propone la visión del cronopio que rompe con el ciclo cronológico, dando vida a la risa que transforma el reloj en un juego. La poesía nace cuando el cronopio llega al corazón del reloj alcaucil que es "la infinita rosa violeta", la rosa de lo imprevisible, la rosa como símbolo de la perfección :

Un fama tenía un reloj de pared y todas las semanas le daba cuerda CON GRAN CUIDADO. Pasó un cronopio y al verlo se puso a reír, fue a su casa e inventó el relojalcachofa o alcaucil, que de una y otra manera puede y debe decirse. El reloj alcaucil de este cronopio es un alcaucil de la gran especie, sujeto por el tallo a un agujero de la pared. Las innumerables hojas del alcaucil marcan la hora presente y además todas las horas, de modo que el cronopio no hace más que sacarle una hoja y ya sabe una hora. Como las va sacando de izquierda a derecha, siempre la hoja da la hora justa, y cada día el cronopio empieza a sacar una nueva vuelta de hojas. Al llegar al corazón el tiempo no puede ya medirse, y en la infinita rosa violeta del centro el cronopio encuentra un gran contento. ${ }^{16}$

En "Relojes" triunfa la libertad de la imaginación del cronopio que se come a su creación, liberándose del tiempo devorador : "entonces se la come con aceite, vinagre y sal, y pone otro reloj en el agujero." ${ }^{17}$ En La vuelta al día en ochenta mundos, Cortázar reivindica una lengua "que sepa inventar, que sepa abrir la puerta para ir a jugar"18, un lenguaje que plantee la subversión del sentido común al desenmascarar el carácter convencional de nuestros hábitos, ideas y actitudes. Triunfa la mirada que ahonda las correspondencias inesperadas cuando los cronopios se cruzan con una tartaruga vista como una pizarra redonda en la cual dibujan una golondrina como gesto de libertad.

11 En una crítica del lenguaje hueco, Cortázar construye el exemplum de un señor que tiene que vivir sin su cabeza y sólo oye las palabras gastadas de un capellán de una cárcel, insinuando que el ser humano ha edificado muros de alienación en su comunicación. El humor de Cortázar se vuelve distópico en el texto "Fin del mundo del fin" que construye una visión negativa de la cultura, adoptando un tono profético. Todo empieza con la situación absurda de un exceso de escribas que no tienen lectores para leerlos ni espacio físico para guardar sus escritos :

El presidente de la república habla por teléfono con los presidentes de las repúblicas, y propone inteligentemente precipitar al mar el sobrante de libros, lo cual se cumple al mismo tiempo en todas las costas del mundo [...] Cada vez más los países serán de escribas y de fábricas de papel y tinta, los escribas de día y las máquinas de noche para imprimir el trabajo de los escribas. Primero las bibliotecas desbordarán de las casas; entonces las municipalidades deciden (ya estamos en la cosa) sacrificar los terrenos de juegos infantiles para ampliar las bibliotecas. Después ceden los teatros, las maternidades, los mataderos, las cantinas, los hospitales. ${ }^{19}$

El absurdo se intensifica cuando los libros pierden su finalidad civilizadora y son usados como ladrillos. La crítica irónica se vuelve más mordaz a partir del momento en que los presidentes del mundo deciden "inteligentemente" lanzar al mar el sobrante de los libros. El narrador se burla de las medidas políticas, denunciando la falta de responsabilidad :

El presidente de la república habla por teléfono con los presidentes de las repúblicas, y propone inteligentemente precipitar al mar el sobrante de libros, lo cual se cumple al mismo tiempo en todas las costas del mundo [...] Esto permite a los escribas aumentar su producción, porque en la tierra vuelve a haber espacio para almacenar sus libros. No piensan que el mar tiene fondo y que en el fondo del mar empiezan a amontonarse los impresos, primero en forma de pasta aglutinante, después en forma de pasta consolidante, y por fin como un piso resistente, aunque viscoso, que sube diariamente algunos metros y que terminará por llegar a la superficie. ${ }^{20}$ 
Cortázar describe una parábola basada en una situación absurda en la cual los escribas son condenados a la mera sobrevivencia : sus impresos perdieron su significado en un mundo que mantiene el poder de los presidentes ahora protegidos en sus inmensos transatlánticos :

Los escribas comprenden que las fábricas de papel y tinta van a quebrar, y escriben con letra cada vez más menuda, aprovechando hasta los rincones más imperceptibles de cada papel. Cuando se termina la tinta escriben con lápiz, etcétera; al terminarse el papel escriben en tablas y baldosas, etcétera. Empieza a difundirse la costumbre de intercalar un texto en otro para aprovechar las entrelíneas, o se borra con hojas de afeitar las letras impresas para usar de nuevo el papel. Los escribas trabajan lentamente, pero su número es tan inmenso que los impresos separan ya por completo las tierras de los lechos de los antiguos mares. En la tierra vive precariamente la raza de los escribas, condenada a extinguirse, y en el mar están las islas y los casinos, o sea los transatlánticos, donde se han refugiado los presidentes de las repúblicas y donde se celebran grandes fiestas y se cambian mensajes de isla a isla, de presidente a presidente y de capitán a capitán. ${ }^{21}$

En Historias de Cronopios y de Famas, triunfa el hombre lúdico contra la precariedad de lo cotidiano : "un hombre metido en un mundo combinatorio, de invención combinatoria, está creando continuamente formas nuevas" ${ }^{22}$. Escribir los textos humorísticos es el juego de amoldar el tiempo de la invención, luchando por "ablandar el ladrillo de todos los días" 23 , el ladrillo de lo previsible, el ladrillo del tedio al ver todos los días : "la misma mujer al lado, los mismos zapatos, el mismo sabor de la misma pasta dentífrica, la misma tristeza de las casas de enfrente, del sucio tablero de ventanas de tiempo con su letrero «Hôtel de Belgique»"24.

\section{Tavares : el juego como reescritura}

En sintonía con el espíritu utópico de Tavares, la ilustradora Rachel Caiano ha dibujado un barrio idealizado donde la violencia de la ciudad contemporánea no tiene morada.

\section{O Bairro de Gonçalo M. Tavares}




\section{O bairkoro}

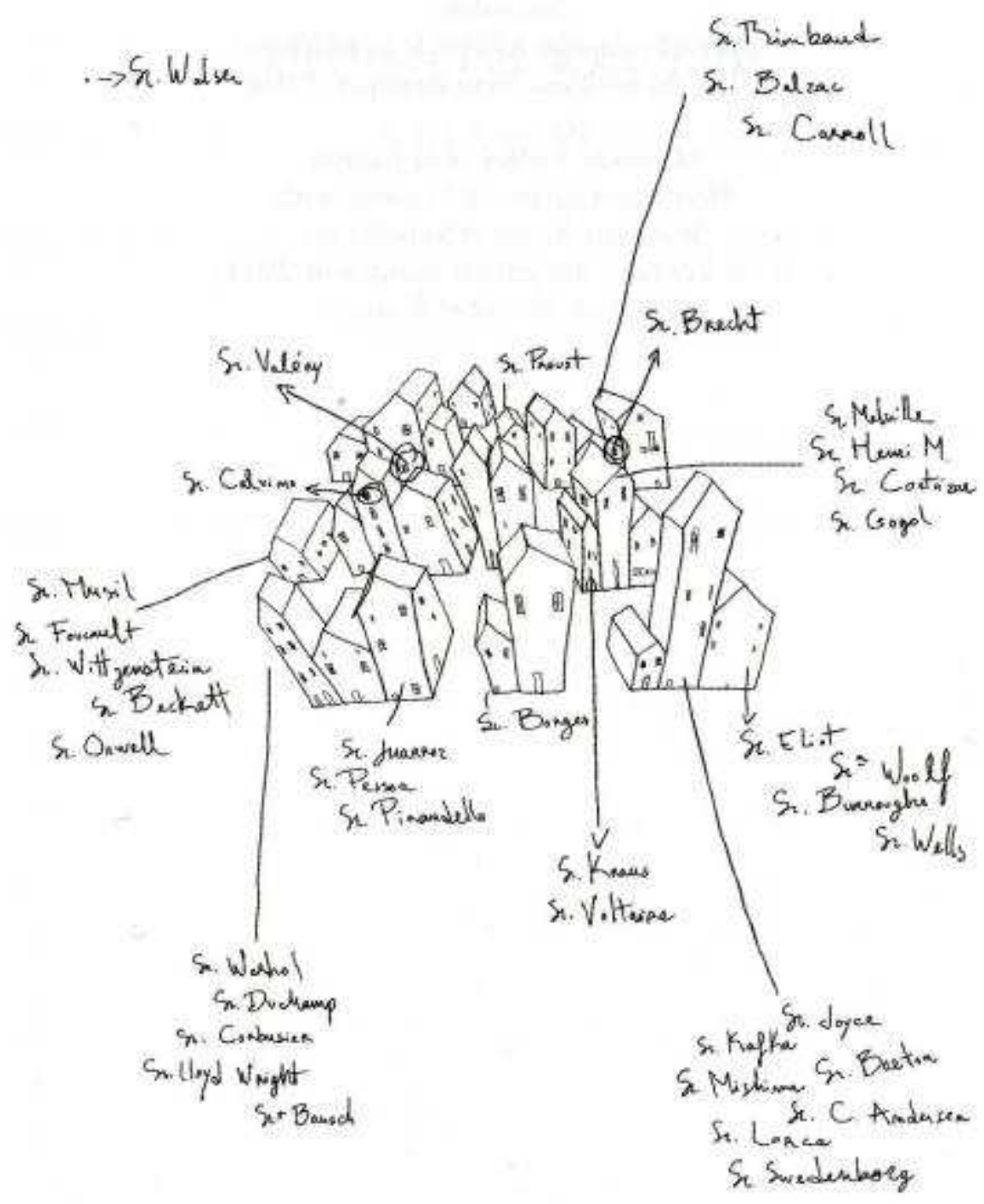

Con esta propuesta de mundo imaginario que promete la publicación de cuarenta libros, Tavares juega a escribir un barrio literario construido según la lógica del humor. $\mathrm{Al}$ imaginar encuentros imprevisibles, O Bairro desmantela la cronología e inaugura la fantasía en libertad, elaborando una relectura crítica de algunos escritores y artistas del pasado en un gesto de homenaje. Tavares ha comentado que su proyecto de barrio se asemeja a la lógica de la aldea de Astérix ${ }^{25}$ que representa un espacio acojedor que resiste a la invasión de los bárbaros.

$17 \quad$ El juego de Tavares es transformar los temas, las indagaciones y los trazos estilísticos de la obra de Juarroz ${ }^{26}$ y Cortázar en un simultáneo rito de celebración y parodia a través de procesos de desautomatización ${ }^{27}$ que los desplaza del centro del canon. Los dobles parodiados de Juarroz y de Cortázar surgen como caricaturas de un señor común, emboscado en sus divagaciones literarias, filosóficas e existenciales ${ }^{28}$. La utopía ucrónica de Tavares es un juego del lenguaje que se rige por las reglas del nexo imprevisible, la microestructura teatral, los espejos de la metaficción y el absurdo que ironiza las actitudes de los señores. Todo el barrio se organiza en breves escenas narrativas cuyo eje central es el doble carnavalizado del escritor, que se pasea en el barrio, siguiendo la unidad de acción, de tiempo y de espacio del teatro. En este montaje de escenas-fragmentos, el lector es espectador y descifrador de los pensamientos, actitudes y acciones de las desfiguraciones de Juarroz y de Cortázar. 
Como serie heterogénea, $O$ Bairro edifica un espacio mítico de un mundo ficcional que transgrede la lógica racionalista y el sistema del canon literario. Situado en el mundo de los imaginarios, $O$ Barrio es una segunda vida que articula la reflexión filosófica basada en algunos procesos del teatro del absurdo. Sin embargo, es pertinente subrayar una distinción : el teatro del absurdo de Ionesco, Beckett y Adamov dinamita mediante la estética del choque las angustias y miserias humanas desde una perspectiva negativa que insiste en la desolación de la condición humana ${ }^{29}$. El fragmento narrativo de $O$ Bairro es la reescritura libre que conjuga lo insólito del lenguaje y lo insólito de las situaciones cómicas, valorizando el juego de la vida ficcional, el juego del lenguaje, el juego dentro del juego, el juego de construir un barrio paralelo a nuestras ciudades en la cual los dilemas de los dobles parodiados revelan, de forma humorística y crítica, nuestros vicios, obsesiones, preocupaciones y búsquedas de sentido.

Tavares juega a apropiarse de los estilos de escritura de sus señores parodiados a través de la hipérbole y el nonsense. Uno de los trazos lúdicos del señor Juarroz es escapar de lo cotidiano, porque lo concibe como tedio, estrechando las afinidades entre el poeta Juarroz y su hermano espiritual Pessoa. Tal como Pessoa, el señor Juarroz piensa y se piensa, compenetrado en sus reflexiones como una circunferencia sin establecer un contacto auténtico con los otros. Evita ser tocado por el exterior, toda su existencia es la concentración en un pensamiento visual y metapoético que lo conduce a la especulación filosófica. Por esta razón, el señor Juarroz es poco hábil para resolver las tareas cotidianas como : tomar café, arreglar un grifo, subir a un tejado, organizar una biblioteca, ir de compras al supermercado. En esta última escena, el habitante del pensamiento se fascina con los colores y las formas de los diversos productos ubicados en los estantes pero sale del supermercado con el canasto vacío. Tavares se divierte recreando en el señor Juarroz la amalgama de la visón del niño y la del pensador que leen el mundo real con la mirada transformadora del cosmogénesis. El señor Juarroz es el vidente que ve más allá de las apariencias pero el efecto disonante es que se encuentra al margen de la máquina de la repetición cotidiana, tal como los cronopios de Cortázar. Su desarraigo se manifiesta cuando intenta persuadir a su paciente esposa de reservar la gaveta de la casa para llenarla de vacío, que es una palabra clave en la poética de Juarroz ${ }^{30}$. Dos visiones del mundo se chocan : la lectura de la gaveta como lugar de depósito y orden de los objetos y la gaveta concebida como arché, pozo-abismo y archivo. Los meses pasan y el señor Juarroz argumenta que la gaveta aún no está completamente llena de vacío, preservando su creencia en un absurdo lúcido. A través de esta paradoja, el señor Juarroz se inscribe en el idealismo de Don Quijote al intentar acabar con el vacío del mundo mientras que su esposa, como Sancho Panza, fracasa en ubicarlo en la realidad pragmática. Este contrapunto tiene un transfondo filosófico : el señor Juarroz pretende almacenar el nihilismo de nuestra sociedad en la gaveta de su casa. De forma insólita, él la concibe como el arca mítico que podría contener la decadencia de los valores humanos. El señor Juarroz intenta negar la nada por un gesto de afirmación instauradora de su mundo interior, que se opone a la impostura de la lógica racionalista.

Otra preocupación del señor Juarroz es el desarraigo del hombre ante lo sagrado. Por tal motivo, medita la hipótesis de un Dios que aparecería todos los días "a toda hora, a tocar à campainha." ${ }^{31}$ Sin embargo, desconecta la caja de la electricidad por no soportar la idea de un Dios omnipresente. De forma alegórica, el habitante filosófico reflexiona sobre el fin de la metafísica en nuestra sociedad : Dios cesó de ser una respuesta para el ser humano que se autodestruye debido a los fanatismos religiosos.

Contrariamente a los otros dobles parodiados, el señor Cortázar aún no figura como protagonista en ningún libro del barrio. Sin embargo, Tavares ya le ha dado vida en cuentos publicados en Brasil y Portugal. El mejor nexo entre el autor de la Vuelta al día en ochenta mundos y la caricatura de Tavares se concentra en el microcuento "Tecnologia e tradição (uma história)"32. Como Cortázar, el señor Cortázar es un bibliófilo inveterado que se encuentra completamente inmerso en la lectura de un libro, interrumpida por un repentino corte de luz. Ante este imprevisto, el señor Cortázar inventa un juego extremo : calcula que le faltan cincuenta páginas para llegar al desenlace y utiliza tres fósforos que le permitirán leer treinta líneas por página. La lectura se convierte en una carrera de atletismo de 100 metros : el lector compulsivo y 
ávido lee "com uma rapidez de leitura invulgar"33 hasta el punto de quemarse los dedos. Disfruta del placer de haber generado un juego en el cual es capaz de correr con las palabras en un ritual de fuego. Tavares construye una cena de lectura bajo el influjo del humor, creando un señor que se sitúa en la tradición de escritores de la literatura del goce, que pone en crisis la relación con el lenguaje, tal como lo propone Barthes en Le Plaisir du texte ${ }^{34}$. Lo cómico ocurre cuando el goce de este lector voraz es frustrado al reponerse la electricidad. Para él, la luz eléctrica es un hecho obsceno que desmonta el rito del juego, ya que apenas le faltaban dos páginas para leer el fin de la narrativa con los fósforos previstos. Furioso, el señor Cortázar se queja a la Central de Electricidad por haber solucionado el desperfecto. Esta breve escena de lectura crea nexos intertextuales con la noción de juego absurdo e imprevisible de la poética de Cortázar, que se inspiró en el juego de la rayuela para proponer dos modelos distintos de leer su novela Rayuela (1962). Del mismo modo, los personajes Olivier, Talita y Traveler inventan los juegos del cementerio, que exhuman vocablos inusuales del castellano. El nexo más fuerte entre Cortázar y su doble parodiado reside en la reescritura de los seres imaginarios que Cortázar modeló, según un planteo surrealista en Historias de Cronopios y de Famas para proponer un manual irónico que ataca la convención burguesa a partir de breves cuentos basados en el absurdo y el nonsense. Como pudimos verificar, el texto de Cortázar deconstruye el lenguaje con fines utilitarios, ya que explora el proceso del disparate y la mirada de las cosas desde lo excéntrico al proponer un manual para subir escaleras, consejos para llorar, cronopios que recetan rosas como medicamento de cura a sus pacientes. Para Cortázar, es necesario perseguir el ritmo secreto de las realidades excepcionales donde se oculta lo insólito que quebranta la rigidez de leyes de la causalidad. Sus cronopios son seres marcados por una postura libre que critican los discursos convencionales y la mecanización de los actos diarios. Los cronopios afirman el humor como forma legítima de transformar el tedio de lo cotidiano en apertura a un real pluridimensional. El señor Cortázar de Tavares es un híbrido entre el Cortázar metaficcional y el cronopio, un ser que vive al margen de la sociedad burguesa entre el arte y la búsqueda de libertad 35 . El doble parodiado de Cortázar se distancia de la técnica que atrofia su facultad de imaginar y el goce de deshojar un libro, instaurando otro tiempo en que se celebra con el asombro de ser hacedor y actor. El acto de lectura se transforma en una situación límite en que el señor Cortázar desmorona la actitud del lector pasivo y conformado. Lleva hasta el paroxismo el placer de leer, reinventándose como un cronopio rebelde, un perseguidor de ritos y una energía que desea y arriesga ganar a pesar de la mala jugada de la tecnología moderna. Con humor irónico, Tavares muestra que las invenciones tecnológicas pueden ser un obstáculo para la liberación del imaginario.

Historias de Cronopios y de Famas y O Bairro son una propuesta de juego plural : Cortázar y Tavares comparten su visión lúdica del mundo, invitando la comunidad de lectores a conectar los distintos hilos del humor que revela la orden escondida del pensamiento, el pensamiento que se burla de los hábitos automatizados, el pensamiento que se sitúa fuera del mundo del antes y del después para afirmarse como el espacio de las afinidades electivas. Cortázar y Tavares son constructores de una arquitectura literaria que articula el humor, el absurdo y la reflexión filosófica como instrumentos de indagación y de desaumatización del lenguaje. Tavares asume la influencia de Cortázar pero crea su propio camino al construir un barrio literario que inaugura una utopía de la levedad profunda. Al jugar a crear un nuevo orden, tanto Cortázar como Tavares dan nacimiento a personajes divertidos que reflejan las trampas de nuestros hábitos, nuestras fallas y la búsqueda de sentido en un espacio sin fronteras, que nos da la promesa de superar el devenir para instalarse en lo eterno : el infinito literario.

Barthes, Roland, Le Plaisir du texte, in Eric Marty (ed.), Oeuvres Complètes, tomo II, Paris : Seuil, 1994.

Caillois, Roger, Les hommes et les jeux, 1958, Paris : Gallimard, 1967. 
Chklovski, Viktor, "L'art comme procédé", in Tzvetan Todorov et alii (ed.), Théorie de la littérature. Textes des Formalistes russes, Paris : Seuil, 1965.

Cortázar, Julio, Rayuela, Madrid : Cátedra, 2005.

Cortázar, Julio, Cuentos Completos/1,1994, Mardrid : Alfagura, 2002.

Cortázar, Julio, La vuelta al día en ochenta mundos, 1967, tomo 1, Buenos Aires : Siglo XXI, 2006.

Cortázar, Julio, Cortázar, Obra crítica, Obras Completas VI, Barcelona : Galaxia Gutenberg, Círculo de Lectores, 2006.

Fadda, Sebastiana, O Teatro do absurdo em Portugal, Lisboa : Cosmos, 2001.

Garfield, Evelyn, ¿Es Cortázar un surrealista?, Madrid : Gredos, 1975.

Juarroz, Roberto, Poesía Vertical, (Diego Sánchez Aguilar, edición), Madrid : Cátedra, 2012.

Maturo, Graciela, Julio Cortázar y el hombre nuevo, Buenos Aires : Fundación Internacional Argentina, 2004.

Prego, Omar, La Fascinación de las palabras, Barcelona : Muchnik, 1985.

Tavares, Gonçalo M., O Senhor Juarroz e o pensamento, 2004, Lisboa : Caminho, 2011.

Tavares, Gonçalo M., "Tecnología e tradição (uma historia)", Revista Novabase Emotion, $\mathrm{n}^{0}$ 21, julio, 2010, p. 42.

\section{Documentos digitales}

El vídeo "O Bairro de Gonçalo M. Tavares" en : https ://www.youtube.com/watch? $\mathrm{v}=\mathrm{EAUK}_{3 j \mathrm{j} v j a \mathrm{M}}$

"Roberto Juarroz" en http ://www.robertojuarroz.com/ensayos1.htm

"Quanto pesa uma palavra?" entrevista concedida a Sissa Frota, disponible en Cronópios : http ://cronopios.com.br/site/artigos.asp?id=4311

\section{Notes}

1 Caillois, Roger, Les hommes et les jeux, 1958, Paris : Gallimard, 1967, p. 60.

2 En Portugal, Tavares ya publicó diez libros de la serie $O$ Bairro : O senhor Valéry e a lógica, $O$ Senhor Henri e a enciclopédia, O Senhor Calvino e o passeio, O Senhor Juarroz e o pensamento, O Senhor Breton e a entrevista, O Senhor Walser e a floresta, o Senhor Krauss e a política, $O$ Senhor Brecht e o sucesso, O Senhor Suwedenborg e as investigações, O Senhor Eliot e as conferências.

3 El lector podrá visualizar el espacio del Bairro en el vídeo siguiente : https ://www.youtube.com/watch?v=EAUK3jvcjaM

4 Maturo, Graciela, Julio Cortázar y el hombre nuevo, Buenos Aires : Fundación Internacional Argentina, 2004, p. 65 .

5 Idem

6 Cortázar, Julio, Cuentos Completos/1, 1994, Mardrid : Alfagura, 2002, p. 417.

7 Idem

8 Idem

9 Cortázar tiene trazos surrealistas sobretodo en la búsqueda de una suprarealidad. En "Muerte de Antonin Artaud" escribió : "[...] la razón del surrealismo excede toda litertura, todo arte, todo método localizado y todo producto resultante. Surrealismo es cosmovisión, no escuela o ismo; una empresa de conquista de la realidad, que es la realidad cierta en vez de la otra de cartón piedra y por siempre ámbar [...]", cf. Julio Cortázar, Obra crítica, Obras Completas VI, Barcelona : Galaxia Gutenberg, Círculo de Lectores, p. 201. 
10 In Prego, Omar, La Fascinación de las palabras, Barcelona, Mucbik, 1985, p. 123.

11 Garfield, Evelyn, ¿̇ Es Julio Cortázar un surrealista ?, Madrid, Gredos, 1975, p. 42.

12 Ibidem, p. 21.

13 Maturo, op. cit, p. 66.

14 Cortázar, op. cit, p. 495.

15 Cortázar, Julio, Rayuela, Madrid : Cátedra, 2005, p. 73.

16 Cortázar, op. cit, p. 481.

17 Idem.

18 Cortázar, Julio, La vuelta al día en ochenta mundos, 1967, tomo 1, Buenos Aires : Siglo XXI, 2006, pp. 158-159.

19 Cortázar, op. cit, p. 449.

20 Idem.

21 Ibidem, p. 450.

22 Prego, Omar, op. cit, p. 136.

23 Cortázar, Julio, op. cit., p. 407.

24 Idem.

25 Sissa Frota entrevista a Gonçalo M. Tavares, intitulada “Quanto pesa uma palabra ?” en : http ://cronopios.com.br/site/artigos.asp?id=4311

26 Considerando que Tavares juega a transformar diversos escritores, este estudio se concentra en la apropriación de los trazos de Juarroz y Cortázar. Cortázar escribió un prólogo que abre la Tercera Poesía vertical de Juarroz. El escritor se fascina con las inversiones y el juego de paradojas de Juarroz. El prólogo puede ser consultado en http ://www.robertojuarroz.com/ensayos1.htm

27 Chklovski, Viktor, "L’art comme procédé", in Tzvetan Todorov et alii (ed.), Théorie de la littérature. Textes des Formalistes russes, Paris : Seuil, 1965, p. 36.

28 El Señor Keuner de Brecht y el Señor Teste de Valéry son nexos intertextuales con los cuales dialoga $O$ Bairro de de Tavares.

29 Fadda, Sebastiana, O Teatro do absurdo em Portugal, Lisboa : Cosmos, 2001, p. 95.

30 Es pertinente consultar la edición de Diego Sánchez Aguilar que presenta de forma profunda los trazos estilísticos de Juarroz en Poesía Vertical, Madrid : Cátedtra, 2012. Aguilar caracteriza la poesía de Juarroz como la filosofía del no ser.

31 Tavares, Gonçalo M., O Senhor Juarroz e o pensamento, Lisboa : Caminho, 2007, p. 61.

32 Tavares, Gonçalo M., “Tecnologia e tradição" (uma história)”, in Revista Novabase E-motion, $\mathrm{n}^{\mathrm{0}} 21$, julio, 2010, p. 42.

33 Idem

34 Barthes, Roland, Le plaisir du texte in Eric Marty (ed.), Oeuvres Complètes, volumen II, 1994, Paris : Seuil, p. 1501.

35 Cortázar comenta sus invenciones : "Es así que el cronopio es la equivalencia del artista, los famas son los burgueses, los funcionarios, y las esperanzas son un poco seres intermedios [...] asimilables en su conducta a los snobs : no saben bien dónde situarse, pero les gusta estar del lado de los prestigiosos", Prego, op. cit., p. 125.

\section{Table des illustrations}

Titre O Bairro de Gonçalo M. Tavares

Uي:_ئ http://journals.openedition.org/amerika/docannexe/image/6253/img-1.jpg

Fichier image/jpeg, 248k

\section{Pour citer cet article}

Référence électronique

Celina Martins, « Julio Cortázar y Gonçalo M. Tavares : el juego de todos los juegos ", Amerika [En ligne], 12 | 2015, mis en ligne le 09 août 2015, consulté le 03 novembre 2021. URL :

http://journals.openedition.org/amerika/6253 ; DOI : https://doi.org/10.4000/amerika.6253 


\section{Auteur}

\section{Celina Martins}

Universidad de Madeira

celi@uma.pt

Articles du même auteur

La mémoire reconfigurée [Texte intégral]

Représentations de la dictature argentine d'après les regards croisés de Julio Cortázar et

Carlos Alonso

Paru dans Amerika, 3 | 2010

\section{Droits d'auteur}

(C) Tous droits réservés 